\title{
Modelling and experimental research in hot precision forging of shaft gear
}

\author{
Baoyu Wang ${ }^{1}$, Zhi Li ${ }^{1}$, Mingnan Zheng ${ }^{1}$, Bin Zuo ${ }^{1}$, Jianguo Linª, and Chuanbao Zhu ${ }^{3}$ \\ ${ }^{1}$ School of Mechanical Engineering, University of Science and Technology Beijing, Beijing 100083, \\ China \\ ${ }^{2}$ Mechanical Engineering Department, Imperial College London, London SW7 2AZ, UK \\ ${ }^{3}$ Shandong Zhongxing Auto Parts Ltd Company, Lixin Town, Laiwu City, Shandong Province 271126, \\ China
}

\begin{abstract}
In this paper, a hot forging die set is designed for a shaft gear. A finite element software DEFORM was employed to simulate the hot forging process. The forming parameter range was determined and the forging force was predicted. The metal flow law in hot forging processes was studied using metal flow analysis and point tracking analysis. The metal flow law was further analysed through finite element simulations and precision forging experiments. The accuracy of hot formed gears is analysed and the deviation of the tooth profile reaches the 8th grade, which meet the defined requirement. The pitch cumulative deviation of the forged part is low enough for practical applications.
\end{abstract}

\section{Introduction}

Shaft gears of hydraulic pumps are fabricated using metal cutting processes, in which metal chips are wasted and the natural material textures are discontinuous. This reduces mechanical properties, such as fatigue strength and corrosion resistance [1]. There has been an increased interest in the production of gears using the net-shape forging technique [2-4]. The advantages of gear forging include reducing manufacturing costs and saving materials, increasing productivity, and better mechanical properties, compared with conventionally cutting processes [5].

Although significant research have been carried out on the forging of gears [6], a gear with long shafts at both ends of gears has significant different features on material flow in hot forging processes, which has not been studied. Thus the main aim of the research is to investigate the material flow in the shaft gear forging and the accuracy analysis of the tooth profile of forged gear through experimentation and modelling.

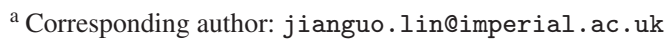

This is an Open Access article distributed under the terms of the Creative Commons Attribution License 4.0, which permits unrestricted use, distribution, and reproduction in any medium, provided the original work is properly cited. 


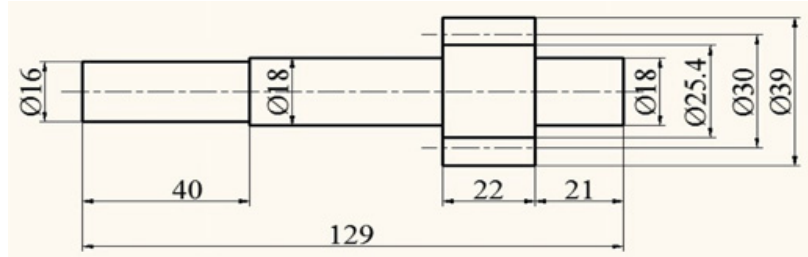

Figure 1. Geometry of the gear shaft to be forged (Dimensions are in $\mathrm{mm}$ ).

Table 1. Characteristic parameters of the shaft gear.

\begin{tabular}{|l|c|}
\hline Parameters & Value \\
\hline Number of teeth & 10 \\
\hline Module $(\mathrm{mm})$ & 3 \\
\hline Pressure angle $\left({ }^{\circ}\right)$ & 20 \\
\hline Addendum modification coefficient & 0.5 \\
\hline Addendum $(\mathrm{mm})$ & 4.5 \\
\hline Dedendum $(\mathrm{mm})$ & 25.4 \\
\hline
\end{tabular}

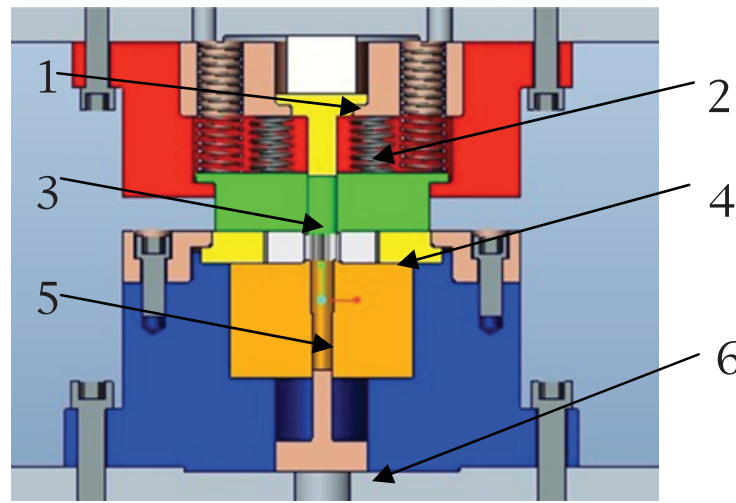

(a) Illustration of tool setup

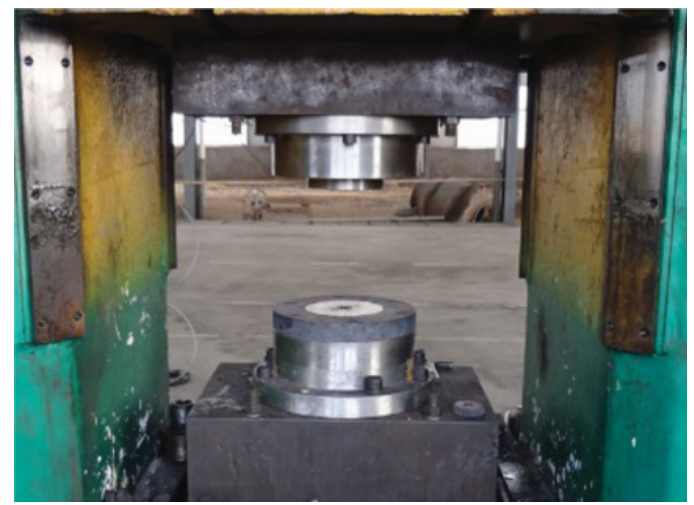

(b) Foging tool

Figure 2. Tool and setup for hot precision forging of the shaft gear: 1. load-cell; 2. punch; 3. upper die; 4. tooth die; 5. lower die; 6. eject pin.

\section{Experimental technique}

A shaft gear is illustrated in Fig. 1 with characteristic parameters listed in Table 1. Due to the long shafts at the two ends of the gear, the die is elastically attached to the press slide, and the details of the tool set and their set-up before the forging is shown in Fig. 2(a).

The shaft gear was forged using a 1000 ton friction press at a rate of $200 \mathrm{~mm} / \mathrm{second}$ with a die set installed. The initial tooling setup for the hot forging is shown in Fig. 2. Water-based graphite lubricant was applied to all tool surfaces in contact with the workpiece. The workpiece was heated to $1000^{\circ} \mathrm{C}$, and die was preheated to about $150^{\circ} \mathrm{C}$. A data collector was installed between the load cell and a computer to record the forging load history. 


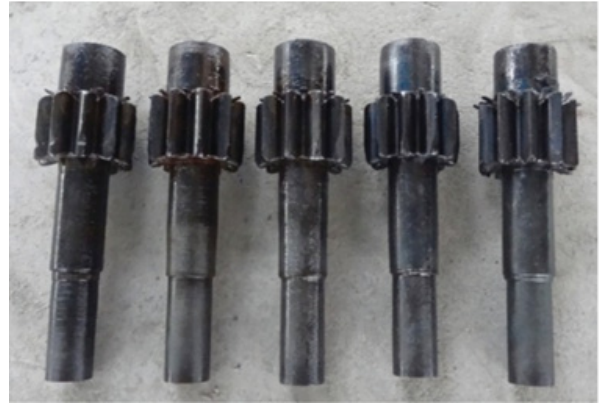

(a) Forged shaft gears

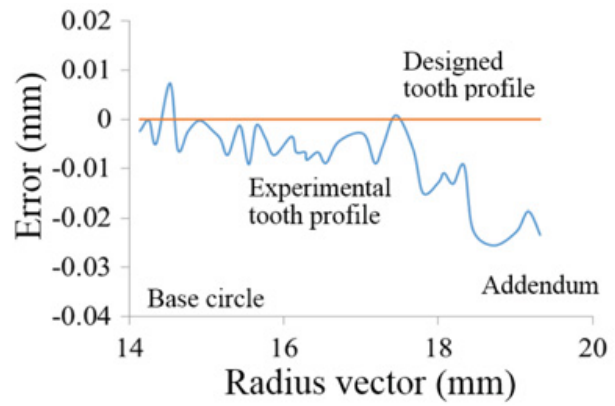

(b) Error of gear tooth profile

Figure 3. The forged shaft gear and the comparison of designed and forged tooth profiles.

\section{Experimental results and analysis}

Forged shaft gears are shown in Fig. 3(a). It can be seen that the gear teeth has been completely formed with a little flash around the parting surface. The tooth profile of forged gear has been digitized and compared with the designed gear tooth profile, which is shown in Fig. 3b. The straight line denotes the standard/designed tooth profile, and the symbols represent the measured tooth profile. Thirty-seven points were collected from the tooth profile locations. The highest deviation is less than $0.02 \mathrm{~mm}$. Deviation of the tooth profile of forged shaft gears meets the design standard - Grade 8 (GB/T10095.12008 standard).

\section{FE model and numerical procedures}

To further evaluate the material flow and teeth filling for the forging of the gear with long shafts at both ends, 3D FE simulation has been carried out. A 3D FE model of the die and the material blank of the shaft gear were established using the PRO/E software system. Finite Element simulation of the forging process was carried out using DEFORM-3D. Figure 4 shows the FE model. Due to symmetry, just one-tenth of the model was used. For the sake of reducing computer CPU time, the forging dies are considered to be rigid and the workpiece material is rigid-plastic, respectively. The workpiece was meshed with 64,846 four nodes tetrahedral elements initially and automatic re-meshing occurs during simulation. The material of the workpiece used in the current study is a low-carbon alloy steel, $42 \mathrm{CrMo} 4$ (AISI 4140), and was heated to $1000^{\circ} \mathrm{C}$. The die was preheated to $150^{\circ} \mathrm{C}$. Forging speed was $200 \mathrm{~mm} / \mathrm{sec}$. The friction conditions prevailing at the interface of die-workpiece was 0.3 at the hot forging condition. The value of heat transfer coefficient between workpiece and dies used in literature, $5 / \mathrm{N} / \mathrm{Sec} / \mathrm{mm} /{ }^{\circ} \mathrm{C}[7]$.

\section{Computational results and analysis}

In the hot forging process, the deformation process of workpiece can be separated into three stages at the boundary points of $10 \%$ stroke and $70 \%$ stroke. Figure 5 shows the die filling and the deformation process of the workpiece during the shaft gear forging.

The initial deformation stage ( $0 \sim 10 \%$ of stroke): the workpiece is deformed in contact with the die cavity wall, which is similar to upsetting of a cylinder with different diameters. The shaft with smaller diameter deforms first.

The second stage (10 70\% of stroke): there were two plastic deformation modes at the same time in this stage, i.e. extrusion deformation on the shaft portions, and the teeth formation at the designed 


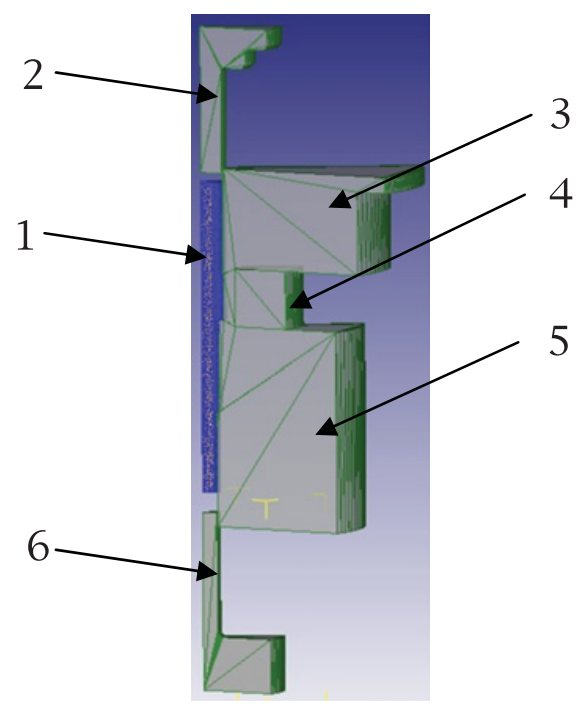

Figure 4. A 3D FE model with defined symetric planes: 1. workpiece; 2. punch; 3. upper die; 4. tooth die; 5. lower die; 6. eject pin.

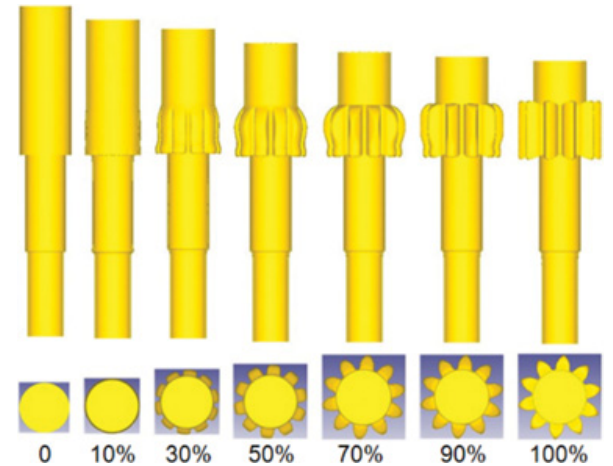

(a) 3D material flow

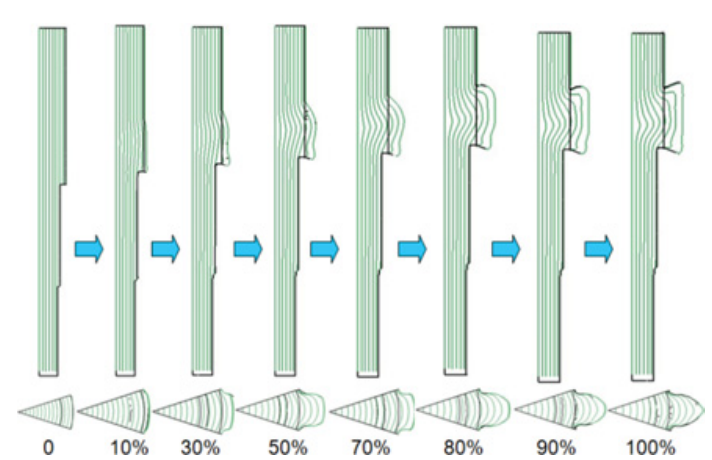

(b) material flow lines

Figure 5. Simulation results of the die filling process in the hot forging of the shaft gear.

location. The teeth were formed gradually as the punch moves down. Because of the tooth width length, "S" shaped profile appeared on each addendum. The forging pressure did not rise obviously (Fig. 6), due to the free-surface expansion.

The third stage ( $70 \sim 100 \%$ of the stroke): the teeth were filled, and "S" shaped profile disappeared. The excessive metal flowed to the lower end of shaft gear.

Metal flow pattern is crucial for shape accuracy and the quality of forged gears in gear forging processes. The metal flow law can be revealed by analying the metal flow lines, which show the elongation direction of the metal. The flow line leads to anisotropy inside workpiece. If tensile stress direction is identical with flow line, performance of workpiece can be improved. Broken metal flow lines reduces performance of workpiece [8-10].

Figure 5(b) shows 2D flow lines of the material at different deformation stages. It can be seen that material flow lines are denser in shaft in radial direction. Because the graph created by metal radial flow 


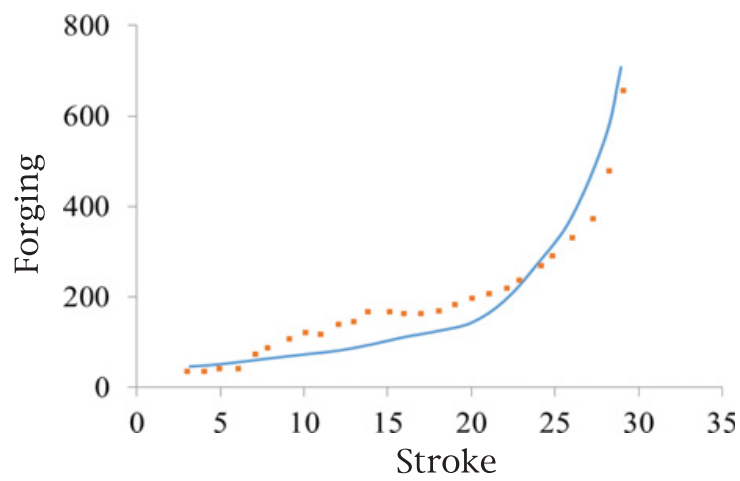

Figure 6. Comparison of experimental (symbols) and FE predicted (curve) forging forces.
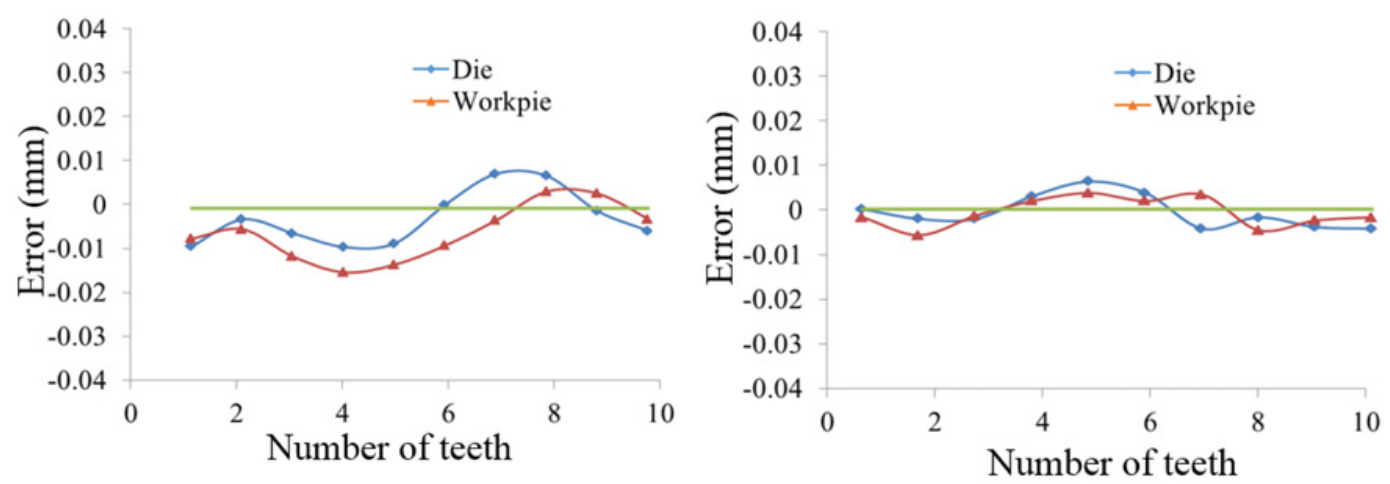

(a) Departure of pitch of single tooth

(b) Cumulative departure of pitch of two teeth
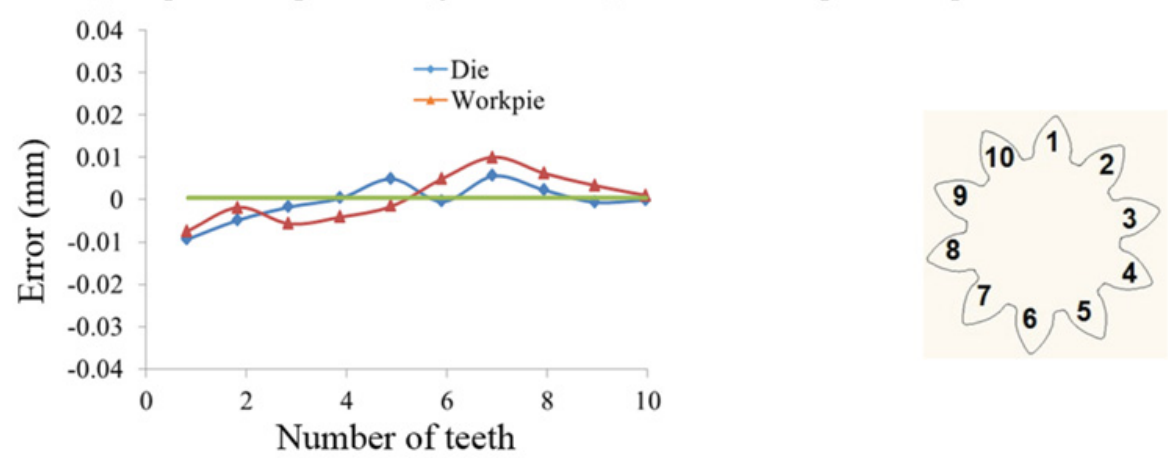

(c) Cumulative departure of pitch three teeth

(d) Serial number

Figure 7. Cumulative departure of the pitch of teeth for die and forged gear.

is divergence. However, metal in shaft area moves subtlely in radial direction. Consequently, flow line is similar to initial graph.

Figure 6 shows forging forces of experimention and FE modelling for the forging of the shaft gear. As the teeth is close to be filled, the forging force rises rapidly. The maximum forging force of experimentation is 70.5 ton, and that of FE simulation is 65.4 ton. The history of the experimental and FE prediced forging forces agrees very well. 


\section{MATEC Web of Conferences}

Further analysis has been carried out for the cumulative departure, which shows algebraic difference between the actual arc length and the standard one of the pitches for multiple teeth. Figure 7 shows the cumulative departure of the tooth pitch for die and forged gear. The departure of the pitch of a single tooth is 9 th class. The cumulative departure of the pitches of two teeth is 6 th class. The cumulative departure of the pitches of three teeth is 5th class. The departure of the pitch for the forged gear is similar to that of the die. Therefore the departure of the pitch of the teeth is due to the errors of the manufactured die.

\section{Conclusions}

A hot forging process has been developed for forming gears with long shafts at the ends. Teeth of forged shaft gears were well filled. The deviation of tooth profile of forged shaft gears is Grade 8, and the departure of the pitch of teeth is similar to that of the die. Through the analysis of FE simulation and experimental results, the deformation process of forging gears with long shafts at both ends could be separated into three deformation stages. In the first stage, it was similar to upsetting of cylinders with different diameters, and forging pressure was below $50 \mathrm{KN}$. The second stage is the combination of extrusion and teeth filling. Due to the tooth width, "S" shaped profiles appeared on the each addendum, and forging pressure was about $320 \mathrm{KN}$. At the end of forging process, the teeth were filled and the maximum forging force reaches $705 \mathrm{KN}$. Difference between of experimental and FE predicted forging forces was about $5 \%$.

The research is financed by National Natural Science Foundation of China (NSFC) (51375042). Authors also acknowledge the support from Shandong Zhongxing Auto Parts Ltd Company, China, for providing test materials, shaft gear design and forging facilities for the forming trials.

\section{References}

[1] Cai, J., T.A. Dean, and Z.M. Hu. Journal of materials processing technology, 150 (2004)

[2] Dean, T.A. Materials \& Design, 21 (2000)

[3] Choi, J.C., Y. Choi. International Journal of Machine Tools and Manufacture, 39 (1999)

[4] Behrens, B.A., E. Doege, S. Reinsch, K. Telkamp, H. Daehndel, and A. Specker. Journal of materials processing technology, 185 (2007)

[5] Behrens, B.A., and D. Odening. International Journal of Material Forming, 2 (2009)

[6] Gronostajski, Z., and M. Hawryluk. Archives of civil and mechanical engineering, 8 (2008)

[7] Zhang Q. China Mechanical Engineering, 15 (2004)

[8] Wang B. Journal of University of Science and Technology Beijing, 36 (2014)

[9] Douglas R., Kuhlmann D. Journal of Materials Processing Technology, 98 (2000)

[10] Choi, J., H. Cho, and J. Choi. Journal of Materials Processing Technology, 103 (2000) 